\title{
Federated Governance: A Successful Model for E-Learning
}

\author{
http://dx.doi.org/10.3991/ijac.v8i4.4914 \\ Michele Wood ${ }^{1}$, Alison Russell ${ }^{1}$, Trudi Verrall ${ }^{1}$, Amanda Thomson ${ }^{2}$, \\ Louise English $^{1}$, Ariana Mancarella ${ }^{1}$, Tracey Clark ${ }^{1}$ \\ ${ }^{1}$ South Australian Health, Australia \\ ${ }^{2}$ Australian Red Cross Blood Service
}

\begin{abstract}
An innovative and sustainable approach to clinical e-learning is described The approach is based on a national federation to provide funding, clinical and educational expertise, IT solutions and program oversight; to develop, curate and champion a resource with multiple courses for healthcare professionals. The approach has resulted in formal recognition by nearly all Australian healthcare organizations and a high course completion rate by individuals. Crucially the approach has succeeded in increasing learner motivation to complete the course and delivered unexpected benefits in process and cost efficiency.
\end{abstract}

Index Terms - collaboration, e-learning, federated governance, quality

\section{INTRODUCTION}

In Australia, the health care industry is faced with the challenge of timely and cost effective delivery of clinical education to a large, disparate and time poor workforce. Whilst studies have found e-learning is as effective as face to face education [1] it is still a challenge to develop and maintain evidence based content underpinned by quality design, which meets the needs of multiple jurisdictions, at low cost. BloodSafe eLearning Australia (BEA) has met this challenge. Through a federated model of governance BEA has been able to deliver a comprehensive on-line education resource under budget, at no cost to end users, designed to improve clinical transfusion practice and patient blood management knowledge to improve patient outcomes.

Blood is freely donated in Australia however the cost of producing fresh blood products in Australia in 2012/2013, was in excess of $\$ 500$ million [2]. Studies have shown significant variation between countries, between hospitals in the same country and even between individual clinicians within the same hospitals in the use of blood transfusion in identical patient groups [3]. Education has been widely used as a strategy to reduce this variation however States and Territories in Australia had implemented different initiatives to address local education needs. With the adoption of BEA as a national eLearning resource for the management of blood and blood products, all jurisdictions have benefited from effective delivery of consistent key messages and quality learning aligned to the Patient Blood Management Guidelines and the National Safety and Quality Health Service (NSQHS) standards to help inform a change in practice.

To date BEA has developed and delivered 14 courses that are self-paced, following adult learning principles supporting different learning pathway, containing multi- media to provide a flexible, authentic learning experience. Participants can engage with content via a range of meaningful activities including videos with expert clinicians discussing or demonstrating current best practice, text and images with links to useful guidelines, tools and references (Figure 1). The courses include opportunities for the learner to apply and test their knowledge by completing activities and clinical based scenarios. All courses include randomized, multiple choice questions as a formal assessment which the learner needs to pass in order to obtain a certificate.

The first course was launched 2007 and by June 2015, BEA had over 310,000 registered with an average of 14,600 course completions per month. With a number of organizations mandating courses in order to meet NSQHS Standard 7 - Blood and Blood Products.

\section{THE FEDERATED MODEL}

Whilst BEA has a focus on quality content and educational design there is an additional aspect that supports all program activities, the culture of collaboration and value is supported by the federated governance of the program

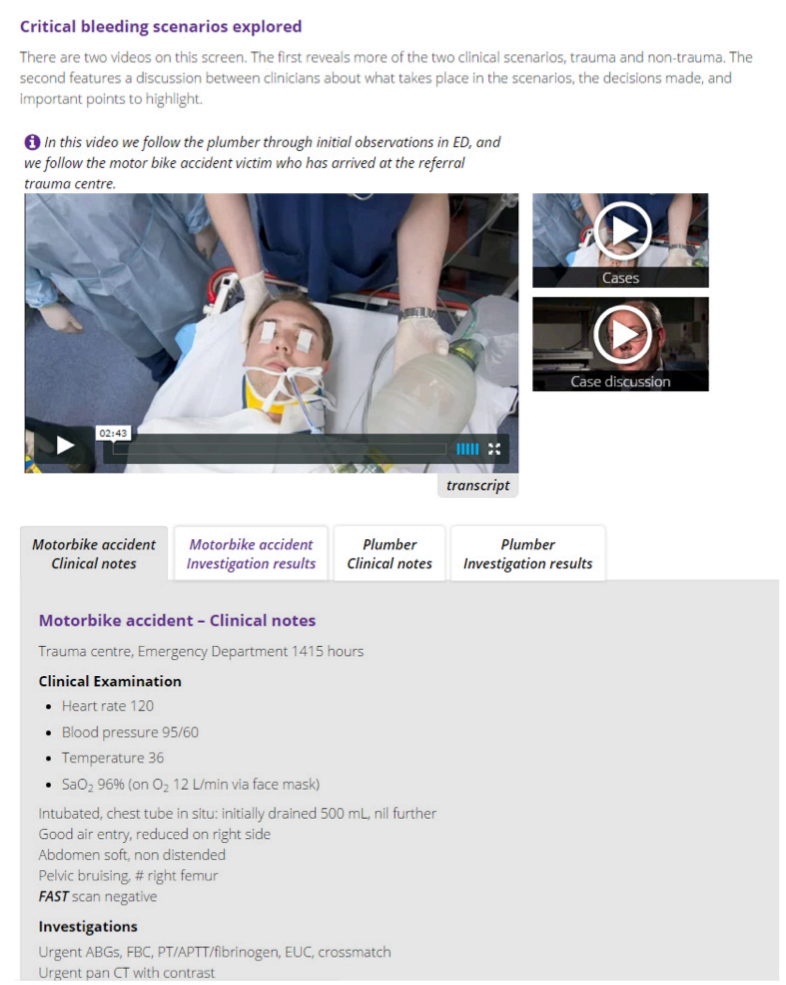

Figure 1. Course content with an example of a clinical scenario 
and the course content, which in turn has increased the byin of jurisdictions and individual motivation to complete the courses.

In 2009, all States and Territories in Australia agreed to provide funding via the National Blood Authority and to collaborate and develop what started as a South Australian state initiative into a national solution. This attitude of national collaboration to produce a joint resource pervades all key activities of BEA - funding, oversight, content development and evaluation. They provide funding and governance and strategic advice, via the National Blood Authority. The aims of the BEA program are aligned to the strategic objectives of the National Blood Authority. This is crucial to BEA's continuing success.

Communication and collaboration ensures a national focus is maintained to prevent gaps and overlaps in knowledge and other educational resources. Links to other education resources are contained in BEA courses and similarly BEA is referenced in other national and local resources. Agreement to national priorities helps coordinate efficient use of clinical experts and focus limited education budgets within organizations. Individual learners are provided with a clearer learning pathway and professional colleges are presented with clearer options for endorsement for continuing professional development.

Clear lines of responsibility exist between the core program team and other parties (Figure 2). Clinical and educational design expertise is provided by the core program team including a lead Medical writer and editor. These parties are based across two Australian states but meet regularly (online and face to face). The BEA team identifies key learning aims and outcomes for individual courses through current research and needs analysis involving healthcare professionals from different specialties across the country.

The core team has developed a wide professional network of clinical experts across Australia (and New Zealand) who contribute to content by:

- Providing examples of best practice

- Appearing in video demonstrations within a course

- Reviewing content for clinical correctness, level of detail and relevance to local work practices

- Providing images, tools and case studies for inclusion in the course

In nearly all instances expert clinical contribution is free of charge - a demonstration of goodwill due to the respect and trust engendered from the federal model of collaboration. BEA is seen as a national resource and therefore there is a strong desire to retain and build on the value of the resource.

BEA releases at least one new course and conducts a major review of an existing course every year. All other courses are continually reviewed and updated to ensure content is current. . Course updates are reviewed by the clinical experts prior to release. A national advisory body (voluntary) meets regularly with the core BEA team to identify and discuss course and system enhancements as well as initiatives which help promote BEA to the target audience. Key partners (such as the Australian Red Cross Blood Service) and state patient blood management collaboratives promote BEA and share local resources for inclusion in the courses where relevant, and at no cost to the program.

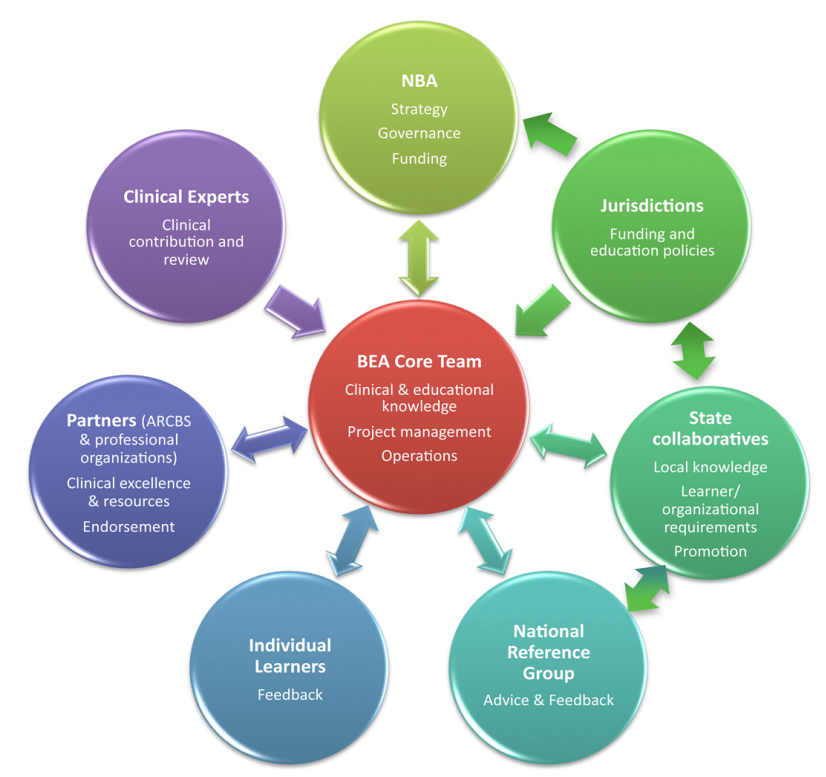

Figure 2. Federated model of governance

Involvement from individual learners is encouraged through a voluntary feedback survey at the end of each course completion. The survey requires answers to standard questions however there is also an opportunity to provide additional comments such as examples of where they could apply their learning. Survey response rates are approximately $1 \%$ of course completions and the majority take the opportunity to provide additional comments and positive feedback. Data collected over the past 12 months includes $90 \%$ believe (agree or strongly agree) the information in the course will improve their knowledge; $63 \%$ will change their clinical practice (agree or strongly agree); $86 \%$ (agree or strongly agree) state it will help them to identify near misses and prevent adverse events; and $89 \%$ (agree or strongly agree) that it will improve patient outcomes/safety.

\section{CONCLUSION}

To develop and maintain an educational resource in a sustainable manner and retain the integrity of the educational quality requires additional inputs over and above funding and technical expertise. For an e-learning package to be readily adopted by time poor health professionals, they need to be confident that it is evidence based, current and relevant to their practice. The federated approach to the governance of courses adopted by BEA provides authenticity, relevance, increased impact and a level of respect from all. It has encouraged engagement by jurisdictions and their clinical experts from across Australia which in turn has resulted in the courses being highly valued by organizations and individuals. Through collaboration by all states and territories, and feedback provided by individual learners, Australia has successfully produced a coordinated, quality educational resource underpinned by the Patient Blood Management guidelines, under budget and at lower cost than individual efforts would have achieved. Through the engagement of the jurisdictions and the high value placed on this resource, funding has been provided to enable these resources to be made available to healthcare professionals at no cost. 


\section{REFERENCES}

[1] David A. Cook, MD MHPE et al, "Internet-Based Learning in the Health Professions: A Meta-analysis,” JAMA. 2008, vol. 300(10), pp1181-1196. http://dx.doi.org/10.1001/jama.300.10.1181

[2] National Blood Authority. "Fresh Blood Product Procurement 2012," [cited 2013 December 02] from http://www.blood.gov.au/fresh-blood-procurement

[3] Snyder-Ramos SA et al. "The ongoing variability in blood transfusion practices in cardiac surgery," Transfusion. 2008, vol. Jul:48(7), pp1284-99. PubMed PMID 18422857

\section{AUTHORS}

Michele Wood (Manager, BloodSafe eLearning Australia, Centre for Education and Training) is with the Women's and Children's Health Network, South Australian Health, Australia (michele.wood@sa.gov.au).

Dr Alison Russell (Director, Centre for Education and Training) is with the Women's and Children's Health Network, South Australian Health, Australia (alison.russell@sa.gov.au).

Trudi Verrall (Clinical Education Lead, BloodSafe eLearning Australia, Centre for Education and Training) is with the Women's and Children's Health Network, South Australian Health, Australia (trudi.verrall@sa.gov.au).

Dr Amanda Thomson (Senior Transfusion Specialist, Haematologist) is with the Australian Red Cross Blood Service (amandarthomson@gmail.com).

Louise English (Clinical Education Officer, BloodSafe eLearning Australia, Centre for Education and Training) is with the Women's and Children's Health Network, South Australian Health, Australia (Louise.english@sa.gov.au).

Ariana Mancarella (Principal Consultant, Blood, Organ \& Tissue Programs) is with the South Australian Department of Health and Ageing, South Australia Health (ariana.mancarella@sa.gov.au).

Tracey Clark (Quality Assurance Officer, BloodSafe eLearning Australia, Centre for Education and Training) is with the Women's and Children's Health Network, South Australian Health, Australia (tracey.clark@sa.gov.au).

This paper describes one of the 2015 IELA Award winning projects (http://www.ielassoc.org/awards program/past winners.html). Submitted 31 July 2015. Published as resubmitted by the authors 30 November 2015 . 